\title{
Modelling Volatility of the BDT/USD Exchange Rate with GARCH Model
}

\author{
Md. Zahangir Alam ${ }^{1} \&$ Md. Azizur Rahman ${ }^{1}$ \\ ${ }^{1}$ Department of Business Administration, International Islamic University Chittagong, Dhaka Campus, \\ Bangladesh \\ Correspondence: Md. ZahangirAlam, Assistant Professor of Finance, Department of Business Administration, \\ International Islamic University Chittagong, Dhaka Campus, House \# $27\left(1^{\text {st }}\right.$ Floor $)$, Road \# 03, Dhanmondi R/A, \\ Dhaka-1205, Bangladesh. Tel: 88-19-6060-8339. E-mail: mzafinance@gmail.com
}

Received: August7, 2012 Accepted: October 4, $2012 \quad$ Online Published: October 15, 2012

doi:10.5539/ijef.v4n11p193 URL: http://dx.doi.org/10.5539/ijef.v4n11p193

\begin{abstract}
The key objective of the study is to explore the application of GARCH type models, like GARCH; EGARCH; TARCH; and PARCH; when applied to task for modelling the BDT/USD exchange rate using the daily foreign exchange rate series fixed up by Bangladesh Bank. This study is conducted by benchmarking their results with AR and ARMA models.The BDT/USD time series from July 03, 2006 to April 30, 2012 are used for the study purpose out of which in-sample and out-of-sample date set cover from July 03, 2006 to May 13, 2010 and May 14, 2010 to April 30, 2012 respectively.The major finding of this study is that all GARCH type models demonstrate that past volatility of exchange rate significantly influence current volatility. Both the AR and ARMA models are found as the best model as per in-sample statistical performance results, whereas according to out-of-sample, GARCH model is the best model with transaction costs. Moreover, Both the ARMA and AR models are nominated as the best model as per in-sample statistical performance results, whereas according to out-of-sample, the TARCH model is nominated as the best model without transaction costs. The EGARCH and TARCH models outperform all the other models as per to in-sample and out-of-sample trading performance outcomes respectively including transaction costs.
\end{abstract}

Keywords: exchange rate, GARCH, EGARCH, TARCH, PARCH, volatility

\section{Introduction}

Volatility of exchange rate can be defined as the variation of price at which two different countries currencies are traded. Volatility models are important to the policy makers, since they use to observe the effect of economic factors on foreign exchange rate as well as to formulate the policies related to the money supply in the economy and the policies associated with the government expenditures and incomes. Corporate policy formulators also employ exchange rate variation models as instruments for constructing portfolio, risk management as well as an input for derivate assets pricing. International transactions oriented countries call attention to more emphasis on the foreign exchange rate variation in formulating various economic policies since their economic growth is affected by the foreign exchange dealings significantly (Kamal et al.,2012). From the view point of extent of government control on exchange rates, foreign exchange rates system may be either fixed foreign exchange rate, freely floating foreign exchange rate, managed floating, or pegged foreign exchange rate system. Fixed foreign exchange rate system is either remains stable or permitted to be changed merely in slight range; market forces solely determine the foreign exchange rate in freely floating foreign exchange rate system; in managed float foreign exchange rate system, foreign exchange rates are permittedto be changedwithout restraint on regular basis and there are no official limitations; whereas the local currency value is attachedwith the foreign currency, and changes in the direction of that currency against other currencies in pegged exchange rate system(Madhura, 2006). Taylor (2005) mentions that foreign exchange rate volatility inputs are helpful in certain financial decisions associated with portfolio optimization, hedging, risk management, pricing of financial derivatives. Kemal (2005) states that foreign exchange rate volatility influences the long-term decision unfavorably by thrilling the volume of worldwide marketing and decisions to allocate resources for investment, and government's sales and procurement policies. Sengupta (2002) states that foreign exchange market has no geographical boundaries and it opens round the clock. There is an inverse relationship between an investor's 
confidence to make investment in a specific country and high volatilities in the foreign exchange rate. For this reason, volatility models are applied for explaining the stable and vital instances of variation in foreign exchange rate.

Modelling volatility of the foreign exchange rate plays an important role in case of portfolio choice, risk management and pricing of assets (Hooper et al., 2009). The present study may be the first initiations in Bangladesh to measure the volatility of BDT/USD exchange rate. Modelling of the volatility of BDT against USD is in fact crucial and important to many diverse groups, like market participants and decision makers. The outcomes of this study render all of the mentioned rationales. The main motive of the study is to estimate the time varying variation in the BDT/USD exchange rate with GARCH type models.

\section{Literature Review}

Modelling and forecasting foreign exchange rate has a lot of realistic application in the field of economics and finance along with extensive discussion in the literature. The basic ARCH/GARCH models are recurrently used and quoted to explain the volatility in financial markets, like, stock exchanges and foreign exchange markets (Kamal et al., 2011).

Mckenzie\& Mitchell (2002) state that the GARCH $(1,1)$ model is preferred in case of symmetric reactions to the improvement of market.. Ellahi (2011) empirically investigates and finds that exchange rate volatility has negative impact on FDI inflow in short run while this impact is positive in the long run. And also finds that adjustment and liberalization program has favorable outcomes in the short run for Pakistan. Hasan (2005) mentions that the real exchange rate volatility has a significant negative impact on real exports.Ngouana (2012) observes that the nominal effective exchange rate of the union was twice as volatile under the hard peg to the euro as it would have been under a hypothetical basket peg over the past decade, driven by the substantial shifts that occurred in WAEMU trade patterns - away from euro area countries and toward the "BICs" (Brazil, India, and China). Balg\& Metcalf (2010) reveals that the volatility of the money supply is a unique determinant in variation of foreign exchange rate. So et al. (1999) conducts a study by highlighting the ARV model as a substitute of GARCH model for forecasting exchange rate volatility and finds that the ARV method gives a noteworthy development in this regard. The outstanding performance seems to be related to the "volatility of volatility', i.e. the volatility changes from day to day.Narayan et al. (2009) conducts a study by using EGARCH and find thatforeign exchange rate volatility is positively affected by conditional shock's evidence. Chong et al. (2004) conducts a research with GARCH model and find that the RM/Sterling exchange rate's volatility is constant and refuse stable variance model sample. The Q statistic as well as LM tests recommends that long memory GARCH models are supposed to be applied as a replacement for a short-range memory as well as high order ARCH model. Neely \& Weller (2009) state that models are inconsistent marginal edge over the genetic program as perMSE and $\mathrm{R}^{2}$ and the genetic program constantly generatesless MAE at all spheres. Kun (2011) conducts a study on modelling volatility of S\&P 500 Index to make comparison between models based forecast and implied volatility and investigated the predictability or model based forecast and the VIX index on forecasting future volatility of S\&P 500 index daily returns by using a variety of time series models, including random walk model, GARCH, GJR, and, EGARCH. He finds thatencompassing regression in favor of squared return shocks recommended that the joint use of GJR $(1,1)$ and RiskMetrics were produced the finest forecasts and also investigated that the implied volatility is inferior for future volatility forecasting, and the model based forecasts have more explanatory power for future volatility.Minkah (2007) reveals that precise forecasting of volatility is indispensable in favor of asset as well as derivative pricing models.Kamal et al. (2011) conducts a study in order to examine the performance of GARCH model including symmetric GARCH-M, asymmetric EGARCH and TARCH models in forecasting the vitality of Pakistani foreign exchange market by using daily foreign exchange rates. The outcomes of the study are the first order autoregressive behavior of the FOREX rate is evidenced in GARCH-M and E-GARCH models, whereas the GARCH-M model supports that previous day foreign exchange rate is affected the current day exchange rate. They also find that the EGARCH-based evaluation of FOREX rates show asymmetric behavior of volatility, where TARCH model shows insignificance but detailed exploratory analysis of the FOREX rate behavior requires prolonged study by applying advance models.

\section{Methodology}

\subsection{Data}

The study is based only the secondary data. The required data,the BDT/USD exchange rate, is collected from data base Reuters Xtra 3000. The study period is from July 03, 2006 to April 30, 2012 which comprise 1513 trading days.The total data set is broken - down into in-sample and out-of-sample data set. The in-sample data set covers 
from July 03, 2006 to May 13, 2010, includes 1009 observations, whereas out-of-sample covers from May 14, 2010 to April 30, 2012 and contains 504 observations.

\subsection{Jarque-Bera Statistics}

Jarque-Bera statistics is used to test the non-normality of the BDT/USD exchange rate.

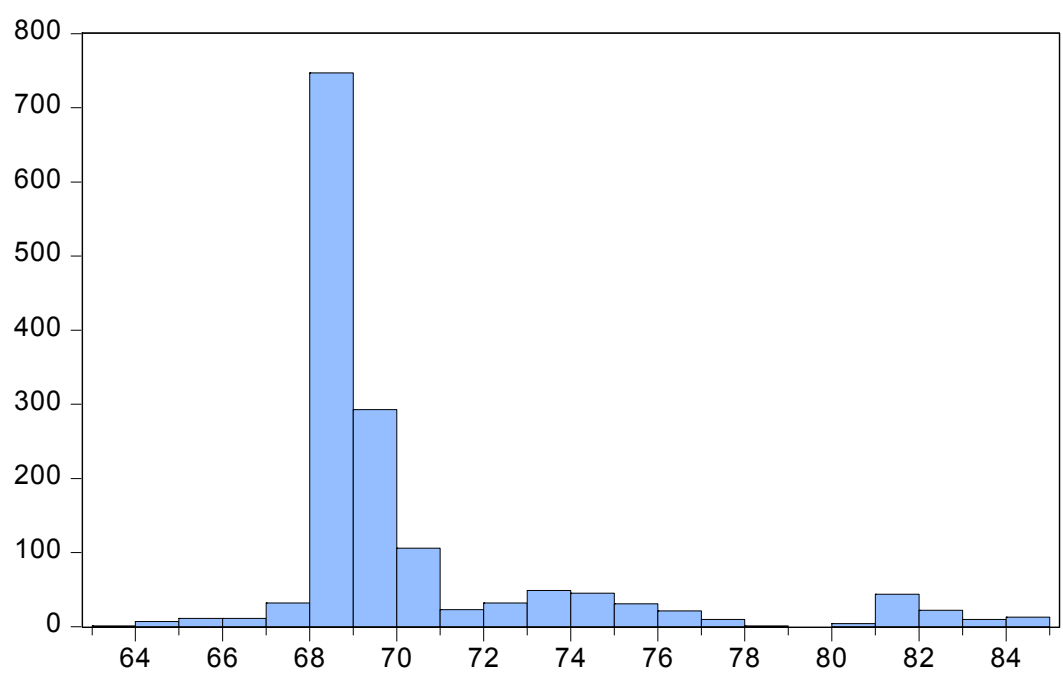

\begin{tabular}{|ll|}
\hline \multicolumn{2}{|l|}{ Series: FOREX } \\
Sample 1 1513 \\
Observations & 1513 \\
& \\
Mean & 70.37912 \\
Median & 68.90000 \\
Maximum & 84.50000 \\
Minimum & 63.94000 \\
Std. Dev. & 3.730811 \\
Skewness & 2.208405 \\
Kurtosis & 7.370926 \\
& \\
Jarque-Bera & 2434.240 \\
Probability & 0.000000 \\
\hline
\end{tabular}

Figure 1. BDT/USD Exchange Rate Summary Statistics

Figure 1 depicts that the positive skewness is 2.208405 and a high positive kurtosis is 7.370926 . According to the Jarque-Bera statistics, the BDT/USD exchange rate return is non-normal at $99 \%$ confidence interval, since probability is 0.0000 which is less than 0.01 . So, it is required to convert the BDT/USD exchange rate series into the return series.

\subsection{Transformation of the BDT/USD Exchange Rate Series}

Generally, the movements of the foreign exchange rates are usuallynon-stationary as well as quite random and not suitable for the study purpose. The series of BDT/USD exchange rates is converted into returns by using the following equation:

Where,

$$
R_{t}=\frac{P_{t}}{P_{t-1}}-1
$$

$\mathrm{R}_{\mathrm{t}}=$ return at time $\mathrm{t}$

$\mathrm{P}_{\mathrm{t}}=$ exchange rate at time $\mathrm{t}$

$\mathrm{P}_{\mathrm{t}-1}=$ exchange rate just preceding of the time $\mathrm{t}$

\subsection{ADF Test andPP Test}

ADF test as well as PP test are used to get confirmation regarding whether BDT/USD exchange rates return series is stationary or not.

Table 1.BDT/USD Exchange Rate Returns ADF TEST

\begin{tabular}{llll}
\hline & & t-Statistic & Prob.* $^{*}$ \\
\hline Augmented Dickey-Fuller test statistic & & -24.92981 & 0.0000 \\
\hline & $1 \%$ level & -3.964137 & \\
& $5 \%$ level & -3.412791 & \\
Test critical values: & $10 \%$ level & -3.128375 & \\
\hline
\end{tabular}

\footnotetext{
*MacKinnon (1996) one-sided p-values.
} 
Table 1 presents the findings of ADF test and formally confirms that the BDT/USD exchange rate returns series is stationary, since the values of ADF test statistic, -24.92981, is less than its test critical value,-3.964137, at the level of significance of $1 \%$.

Table 2. BDT/USD Exchange Rate Returns PP Test

\begin{tabular}{llll}
\hline & & Adj. t-Stat & Prob.* \\
\hline Augmented Dickey-Fuller test statistic & & -53.21143 & 0.0000 \\
\hline & $1 \%$ level & -3.964125 & \\
& $5 \%$ level & -3.412785 & \\
Test critical values: & $10 \%$ level & -3.128372 & \\
\hline
\end{tabular}

*MacKinnon (1996) one-sided p-values.

Table 2 demonstrates the findings of the PP test and properly proves that the BDT/USD exchange rate returns series is stationary, since the values of PP test statistic, -53.21143 , less than its test critical value, -3.964125 , at the level of significance of $1 \%$. Therefore, it can be mentioned that the BDT/USD exchange rates returns series is stationary as per both the ADF test as well as PP test.

\subsection{Summary Statistics of the BDT/USD Exchange Rate Returns}

Summary statistics of the BDT/USD exchange rate returns is used to test whether BDT/USD exchange rate returns series is non-normal at $99 \%$ confidence level or not.

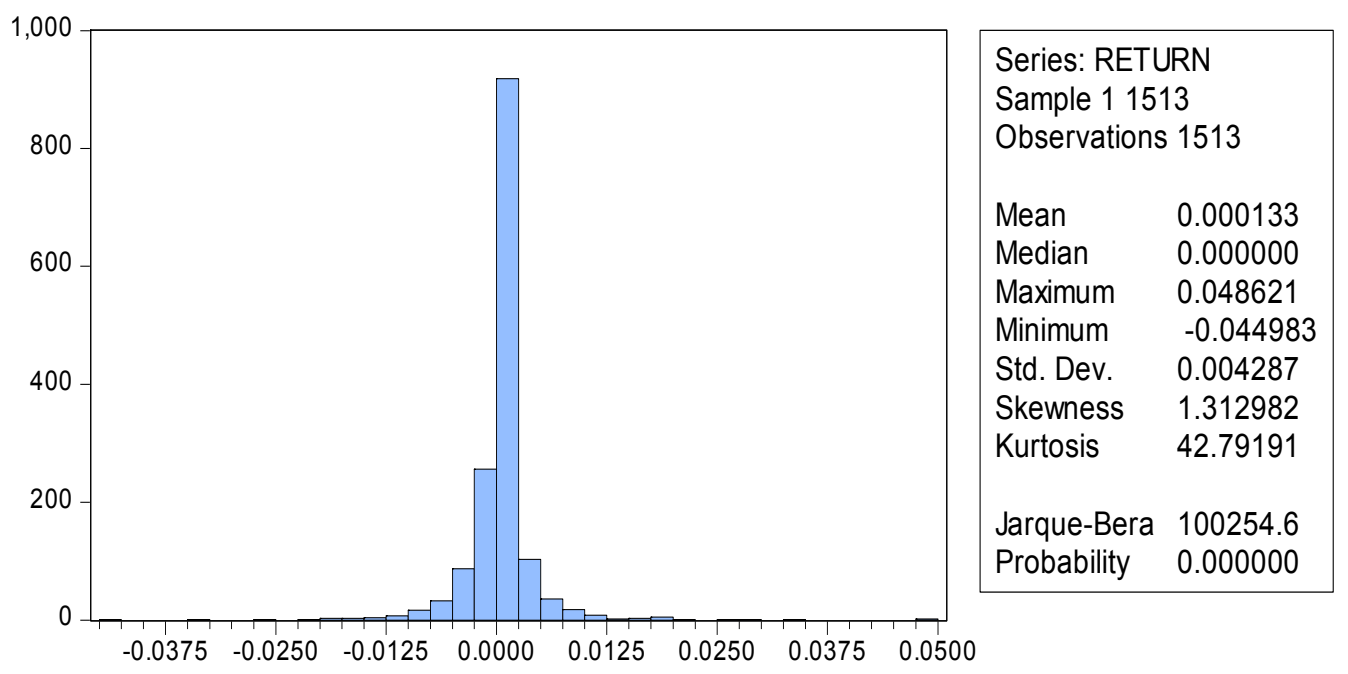

Figure 2. BDT/USD Exchange Rates Returns Summary Statistics

Figure 2 further discloses a slight positive skewness which is 1.312982 and a higher positive kurtosis which is 42.79191. According to the Jarque-Bera statistics, the BDT/USD returns series is non-normal at the confidence interval of $99 \%$, since probability is 0.0000 which is less than 0.01 .

\subsection{Specification of the Model}

\subsubsection{Benchmark Models}

GARCH, EGARCH, PARCH and TARCH models are benchmarked with an autoregressive (AR) model, and an autoregressive moving average (ARMA) model in the study.

\subsubsection{AR Model}

According to AR model,forecasting is a function of previous values ofatime series (Hanke\&Wichern, 2009) and it takes the following equation:

$$
y_{t}=\mu+\varphi_{1} y_{t-1}+\varphi 2 y_{t-2}+\cdots+\varphi_{p} y_{t-p}+u_{t}
$$




\subsubsection{ARMA Model}

This model indicates that the present value of a time series depends upon it past values (Sermpinis, Dunis and Laws, 2010).This model takes the following equation:

$$
Y t=\varphi_{0}+\varphi_{1} Y_{t-1}+\varphi_{2} Y_{t-2}+\cdots+\varphi_{p} Y_{t-p}+\varepsilon_{t}-w_{1} \varepsilon_{t-1}-w_{2} \varepsilon_{t-2}-\cdot \cdot-w_{q} \varepsilon_{t-q}
$$

\subsubsection{GARCH Model}

Bollerslev (1986) \& Taylor (1986) develops GARCH model independently and this model permits the conditional variance to be dependent upon previous own lags, and GARCH $(1,1)$ takes the following equation:

$$
\sigma_{t}^{2}=\alpha_{0}+\alpha_{1} u_{t-1}^{2}+\beta \sigma_{t-1}^{2}
$$

$\sigma_{t}^{2}$ is the conditional variance and this model can interpret the current fitted variance, $h t$, as a weighted function of a long-term average value which is dependent on $\alpha_{0}$, information about volatility during the previous period $\alpha_{1} u_{t-1}^{2}$ and the fitted variance from the model during the previous period, $\beta \sigma_{t-1}^{2}$, (Brooks, 2008).

\subsubsection{PARCH Model}

The PARCH model is an extension of GARCH with an extra term added to account for possible asymmetries and it takes the following form:

\subsubsection{EGARCH Model}

$$
\sigma_{t}^{2}=\alpha_{0}+\alpha_{1} u_{t-1}^{2}+\beta \sigma_{t-1}^{2}+\gamma u_{t-1}^{2} I_{t-1}
$$

Nelson (1991) develops exponential GARCH (EGARCH) model. The conditional variance equation can be expressed in the following way:

$$
\ln \sigma_{t}^{2}=\omega+\beta \ln \sigma_{t-1}^{2}+\gamma \frac{u_{t-1}}{\sqrt{\sigma_{t-1}^{2}}}+\alpha\left[\frac{\left|u_{t-1}\right|}{\sqrt{\sigma_{t-1}^{2}}}-\sqrt{\frac{2}{\pi}}\right]
$$

This model more advantageous compared to the pure GARCH specification. Firstly, as the $\log \left(\sigma_{t}^{2}\right)$ is modeled, then even if the parameters are negative, $\sigma_{t}^{2}$ would be positive. Therefore, artificially imposition of non-negativity constraints on the model parameters is not required. Secondly, asymmetries are allowed for under the EGARCH formulation, as if the association between volatility and returns is negative, $\gamma$, will be negative ((Brooks, 2008).

\subsubsection{TARCH Model}

Zakoïan (1994) \&Glosten et al. (1993) use the TARCH model with an intention of independence than for the asymmetric effect of the "news". The TARCH takes the following form:

$$
\sigma_{t}^{2}=\omega+\sum_{j=1}^{p} \beta_{j} \sigma_{t-j}^{2}+\sum_{i=1}^{q} \alpha_{i} u_{t-i}^{2}+\sum_{k=1}^{r} \gamma_{k} u_{t-k}^{2} \overline{I_{t-k}}
$$

\subsection{Statistical and Trading Performance of the Model}

\subsubsection{Measures of the Statistical Performance of the Model}

The statistical performance measures are, namely mean absolute error (MAE); mean absolute percentage error (MAPE); root mean squared error (RMSE); and theil-u, arecalculated to indentify the best model in case of in-sample as well as the out-of-sample case individually in this study. Lower the values of RMSE, MAE, MAPE and Theil-U better the forecasting accuracy of a given model.

\subsubsection{Measures of the Trading Performance of the Model}

The trading performance measures, like annualized return $\left(R^{A}\right)$; annualized volatility $\left(\sigma^{A}\right)$; information ratio (SR); and maximum drawdown (MD), are used to select the best model. That model's trading performance would be the best whose annualized return, cumulative return, ratio information is the highest, and on the other hand whose annualized volatility and maximum drawdown would be the lowest.

\subsection{Transaction Cost}

In this study, the transaction cost is 2 spread per round trip. The trading performance measures are used to select the best model with transaction cost in the in-sample case and the out-of-sample case individually in this study.

\section{Empirical Results}

\subsection{AR(1) Model}

The table below shows the output of the AR (1) BDT/USD returns estimation: 
Table 3. Output of the AR (1) BDT/USD Returns Estimation

\begin{tabular}{lcccc}
\hline \multicolumn{1}{c}{ Variable } & Coefficient & Std. Error & t-Statistic & Prob. \\
\hline $\mathrm{C}$ & 0.000029 & 0.000107 & 0.271749 & 0.7859 \\
$\mathrm{AR}(1)$ & -0.283417 & 0.030235 & -9.373657 & 0.0000 \\
\hline
\end{tabular}

The estimated AR (1) model takes the following form:

$$
R_{t}=0.000029-0.283663 R_{t-1}
$$

The coefficient (with the exception of the constant) of the estimated AR (1) is significant at the confidence interval of $95 \%$, since the probability of its coefficient (except the constant) is less than 0.05 .

\subsection{ARMA $(1,1)$ Model}

The following table shows output ofARMA $(1,1)$ BDT/USD returns estimation:

Table 4. ARMA $(1,1)$ BDT/USD Returns Estimation

\begin{tabular}{lcccc}
\hline \multicolumn{1}{c}{ Variable } & Coefficient & Std. Error & t-Statistic & Prob. \\
\hline $\mathrm{C}$ & 0.0000178 & 0.0000823 & 0.216817 & 0.8284 \\
$\mathrm{AR}(1)$ & 0.185505 & 0.086423 & 2.146480 & 0.0321 \\
$\mathrm{MA}(1)$ & -0.505836 & 0.075954 & -6.659750 & 0.0000 \\
\hline
\end{tabular}

The estimated ARMA $(1,1)$ model is as follows:

$$
R_{t}=0.0000178+0.185505 Y_{t-1}-0.505836 Y_{t-2}
$$

The all coefficients (with the exception of constant) of the estimated ARMA $(1,1)$ model are statistically significant at $95 \%$ confidence interval, since the probability of its each coefficient (except the constant) is less than 0.05 .

\subsection{GARCH Model}

Table 5. Output of GARCH Model Estimation

\begin{tabular}{lcccc}
\hline \multicolumn{1}{c}{ Variable } & Coefficient & Std. Error & z-Statistic & Prob. \\
\hline $\mathrm{C}$ & 0.0000826 & 0.0000248 & 3.331119 & 0.0009 \\
\hline \multicolumn{5}{c}{ Variance Equation } \\
\hline $\mathrm{C}$ & 0.000000347 & 0.0000000166 & 20.82415 & 0.0000 \\
RESID(-1)^2 & 0.266450 & 0.012782 & 20.84645 & 0.0000 \\
GARCH(-1) & 0.748788 & 0.008688 & 86.18310 & 0.0000 \\
\hline
\end{tabular}

Table 5 reveals that in the mean equation, the constant $\mathrm{C}$ is also significant at $1 \%$ since its probability is less than 0.01 . In the variance equation, the coefficient of the terms, $\operatorname{RESID}(-1)^{\wedge} 2$ is significant at $1 \%$ in the GARCH model showing that the volatility of risk is affected, significantly, by past square residual terms. The GARCH(-1) is also significant at $1 \%$ level, which shows that past volatility of exchange rate is significantly, influencing current volatility.

\subsection{TARCH Model}

Table 6. Output of TARCH Model Estimation

\begin{tabular}{lcccc}
\hline \multicolumn{1}{c}{ Variable } & Coefficient & Std. Error & z-Statistic & Prob. \\
\hline $\mathrm{C}$ & 0.0000504 & 0.0000296 & 1.704388 & 0.0883 \\
\hline \multicolumn{4}{c}{ Variance Equation } \\
\hline $\mathrm{C}$ & 0.000000345 & 0.0000000161 & 21.36237 & 0.0000 \\
$\mathrm{RESID}(-1)^{\wedge} 2$ & 0.176019 & 0.016684 & 10.55046 & 0.0000 \\
$\mathrm{RESID}(-1)^{\wedge} 2^{*}(\operatorname{RESID}(-1)<0)$ & 0.207446 & 0.030388 & 6.826507 & 0.0000 \\
\hline GARCH$(-1)$ & 0.748205 & 0.008476 & 88.27506 & 0.0000 \\
\hline
\end{tabular}


Table 6 depicts that in the mean equation, the constant $\mathrm{C}$ is not significant at $1 \%$ since its probability is greater than 0.01 , whereas in the variance equation, the constant $\mathrm{C}$ is significant at $1 \%$ since its probability is less than 0.01 . In the variance equation, all the coefficients of the terms, $\operatorname{RESID}(-1)^{\wedge} 2, \operatorname{RESID}(-1)^{\wedge} 2^{*}(\operatorname{RESID}(-1)<0)$, and GARCH(-1), are statistically significant at $1 \%$ in the TARCH model, since their probabilities are less than 0.01 which indicates that past volatility of exchange rate is significantly, influencing current volatility.

\subsection{PARCH Model}

Table 7. Output of PARCH Model Estimation

\begin{tabular}{lllll}
\hline Variable & Coefficient & Std. Error & z-Statistic & Prob. \\
\hline $\mathrm{C}$ & 5.14E-05 & 3.07E-05 & 1.674610 & 0.0940 \\
\hline \multicolumn{5}{c}{ Variance Equation } \\
\hline $\mathrm{C}(4)$ & $1.05 \mathrm{E}-08$ & $1.23 \mathrm{E}-08$ & 0.856799 & 0.3916 \\
$\mathrm{C}(5)$ & 0.269774 & 0.017487 & 15.42752 & 0.0000 \\
$\mathrm{C}(6)$ & 0.191263 & 0.025298 & 7.560265 & 0.0000 \\
$\mathrm{C}(7)$ & 0.708489 & 0.015815 & 44.79890 & 0.0000 \\
$\mathrm{C}(8)$ & 2.559976 & 0.183877 & 13.92225 & 0.0000 \\
\hline
\end{tabular}

Table 7 depicts that both in the mean as well as variance equations, the constant $\mathrm{C}$ is not significant at $1 \%$ since their probabilities are greater than 0.01. In the variance equation, all the coefficients of the terms, $(\operatorname{ABS}(\operatorname{RESID}(-1)), \operatorname{RESID}(-1))^{\wedge} \mathrm{C}(6)$, and $@ \operatorname{SQRT}(\operatorname{GARCH}(-1))^{\wedge} \mathrm{C}(8)$ are statistically significant at $1 \%$ in the PARCH model, since their probabilities are less than 0.01 which indicates that past volatility of exchange rate is significantly, influencing current volatility.

\subsection{EGARCH Model}

Table 8. Output of EGARCH Model Estimation

\begin{tabular}{lcccc}
\hline Variable & Coefficient & Std. Error & z-Statistic & Prob. \\
\hline $\mathrm{C}$ & 0.000182 & 0.000016 & 11.36593 & 0.0000 \\
\hline \multicolumn{5}{c}{ Variance Equation } \\
\hline $\mathrm{C}(4)$ & -0.976753 & 0.043536 & -22.43573 & 0.0000 \\
$\mathrm{C}(5)$ & 0.425092 & 0.013219 & 32.15794 & 0.0000 \\
$\mathrm{C}(7)$ & -0.049511 & 0.013178 & -3.757123 & 0.0002 \\
& 0.940384 & 0.003327 & 282.6224 & 0.0000 \\
\hline
\end{tabular}

Table 8 reveals that both in the mean as well as variance equations, the constant $\mathrm{C}$ is significant at $1 \%$ since their probabilities are less than 0.01. In the variance equation, all the coefficients of the terms, ABS(RESID(-1)/@SQRT(GARCH(-1))), RESID(-1)/@SQRT(GARCH(-1)), and LOG(GARCH(-1)) are statistically significant at $1 \%$ in the EGARCH model, since their probabilities are less than 0.01 which indicates that past volatility of exchange rate is significantly, influencing current volatility. The EGARCH variance equation also indicates that there exists the asymmetric behavior in volatility, which means that positive shocks are effecting, differently, than the negative on volatility.

\subsection{Statistical Performance}

\subsubsection{In -Sample Statistical Performance}

Table 9. In -Sample Statistical Performance Results

\begin{tabular}{lllllll}
\hline \multicolumn{1}{c}{ Particulars } & \multicolumn{5}{c}{ Model } \\
\hline & AR & ARMA & GARCH & EGARCH & PARCH & TARCH \\
\hline Mean Absolute Error & 0.0024 & 0.0024 & 0.0026 & 0.0026 & 0.0025 & 0.0025 \\
Mean Absolute Percentage Error & $67.43 \%$ & $69.32 \%$ & $73.35 \%$ & $76.60 \%$ & $70.99 \%$ & $71.23 \%$ \\
Root Mean Squared Error & 0.0057 & 0.0057 & 0.0059 & 0.0059 & 0.0058 & 0.0058 \\
Theil's Inequality Coefficient & 0.9817 & 0.9599 & 0.9623 & 0.9609 & 0.9706 & 0.9695 \\
\hline
\end{tabular}


Table 9 reveals that both the AR and ARMA models have the same and the lowest mean absolute error (MAE) at 0.0024, whereas AR has the lowest MAPE at 67.43\%. Both the AR and ARMA models have the same and the lowest root mean squared error (RMSE) at 0.0057, whereas the ARMA model has the lowest theil's inequality coefficient at 0.7058.It is complex to select the best performing model on the basis of these results, since both the AR and ARMAmodels are nominated as the best model three times, the GARCH modelisnominated as the best model once, whereas the EGARCH, PARCH and TARCH are nominated not a single time.

\subsubsection{Out - Of- Sample Statistical Performance}

Table 10. Out -of - Sample Statistical Performance Result

\begin{tabular}{lllllll}
\hline Particulars & \multicolumn{7}{c}{ Model } \\
\cline { 2 - 7 } & AR & ARMA & GARCH & EGARCH & PARCH & TARCH \\
\hline Mean Absolute Error & 0.0008 & 0.0008 & 0.0008 & 0.0012 & 0.0009 & 0.0008 \\
Mean Absolute Percentage Error & $33.83 \%$ & $37.16 \%$ & $36.97 \%$ & $57.90 \%$ & $42.40 \%$ & $36.02 \%$ \\
Root Mean Squared Error & 0.0019 & 0.0018 & 0.0018 & 0.0027 & 0.0021 & 0.0018 \\
Theil's Inequality Coefficient & 0.7391 & 0.7191 & 0.6935 & 0.7050 & 0.7799 & 0.7061 \\
\hline
\end{tabular}

Table 10 depicts that all models have the lowest mean absolute error (MAE) at 0.0008, except the EGRACH and PARCH models, whereas AR model has the lowest MAPE at 33.83\%. The ARMA, GARCH, and TARCH models have the same and the lowest root mean squared error (RMSE) at 0.0018, whereas the GARCH model has the minimum theil's inequality coefficient at 0.6935 . The GARCH model is selected as the best performing model on the basis of these results, since this model is nominated as the best model three times, whereas the EGARCH and PARCH models are nominated not a single time.

\subsection{Trading Performance}

4.8.1 In-Sample Trading Performance without Transaction Costs

Table 11. In- Sample Trading Performance Results without Transaction Costs

\begin{tabular}{|c|c|c|c|c|c|c|}
\hline \multirow[t]{2}{*}{ Particulars } & \multicolumn{6}{|c|}{ Model } \\
\hline & AR & ARMA & GARCH & EGARCH & PARCH & TARCH \\
\hline Annualised Return & $-45.27 \%$ & $-39.43 \%$ & $-40.54 \%$ & $-39.52 \%$ & $-41.90 \%$ & $-41.34 \%$ \\
\hline Annualised Volatility & $6.59 \%$ & $6.74 \%$ & $6.71 \%$ & $6.73 \%$ & $6.68 \%$ & $6.69 \%$ \\
\hline Sharpe Ratio & -6.87 & -5.85 & -6.04 & -5.87 & -6.27 & -6.18 \\
\hline Maximum Drawdown & $-181.66 \%$ & $-163.53 \%$ & $-167.99 \%$ & $-163.92 \%$ & $-173.42 \%$ & $-171.19 \%$ \\
\hline
\end{tabular}

Table 11 depicts that the ARMA model has the highest annualized return at $39.43 \%$, whereas AR model has the lowest annualized volatility at $6.59 \%$. The ARMA model has the highest Sharpe ratio at -5.85 .The AR model has the minimum downside risk s measured by maximum drawdown at $-181.66 \%$. Therefore, both the ARMA and AR models might be selected as the best model, since they are nominated as the best models the highest times.

\subsubsection{Out-Of-Sample Trading Performance without Transaction Costs}

Table 12. Validation Trading Performance Results without Transaction Costs

\begin{tabular}{|c|c|c|c|c|c|c|}
\hline \multirow[t]{2}{*}{ Particulars } & \multicolumn{6}{|c|}{ Model } \\
\hline & $\mathrm{AR}$ & ARMA & GARCH & EGARCH & PARCH & TARCH \\
\hline Annualised Return & $14.03 \%$ & $16.62 \%$ & $19.42 \%$ & $4.86 \%$ & $-2.67 \%$ & $20.09 \%$ \\
\hline Annualised Volatility & $5.93 \%$ & $5.90 \%$ & $5.87 \%$ & $5.99 \%$ & $5.99 \%$ & $5.86 \%$ \\
\hline Sharpe Ratio & 2.37 & 2.82 & 3.31 & 0.81 & -0.45 & 3.43 \\
\hline Maximum Drawdown & $-4.76 \%$ & $-3.52 \%$ & $-3.55 \%$ & $-4.43 \%$ & $-11.52 \%$ & $-3.48 \%$ \\
\hline
\end{tabular}

Table 12 depicts that the TARCH model has the highest annualized return, lowest annualized volatility, and highestat Sharpe ratio at 20.09\%, 5.86\%, and 3.43 respectively. The PARCH model has the lowest downside risk 
as measured by maximum drawdown at $-11.52 \%$. Therefore, the TARCH model is selected as the best performing model on the basis of these results, since this model is nominated as the best model the maximum times.

\subsubsection{In -Sample Trading Performance with Transaction Costs}

The average BDT/USD exchange rate for the in-sample time period is 70.37912 , therefore the transaction cost is $0.00028 \%$ per transaction.

Table 13. In-Sample Trading Performance Results with Transaction Costs

\begin{tabular}{|c|c|c|c|c|c|c|}
\hline \multirow[b]{2}{*}{ Particulars } & \multicolumn{6}{|c|}{ Model } \\
\hline & AR & ARMA & GARCH & EGARCH & PARCH & TARCH \\
\hline Transaction Costs & 0.110544 & 0.084116 & 92352 & 84864 & 102336 & 87584 \\
\hline Annualized Return & $-56.32 \%$ & $-47.84 \%$ & $-49.41 \%$ & $-47.25 \%$ & $-51.22 \%$ & $-50.49 \%$ \\
\hline
\end{tabular}

According to the table 13, it can be stated that after considering transaction costs in case of in-sample trading performance, the EGARCH model does better thanother models in respect of annualized return, since it has the highest annualized return (including transaction costs) at $-47.25 \%$.

4.8.4 Out -of- Sample Trading Performance with Transaction Costs

The average BDT/USD exchange rate during the period of out-of-sample is 68.56817641 , so transaction costs are $0.00029 \%$ per transaction.

Table 14. Out -of- Sample Trading Performance with Transaction Costs

\begin{tabular}{lcccccc}
\hline Particulars & \multicolumn{4}{c}{ Model } \\
\cline { 2 - 6 } & AR & ARMA & GARCH & EGARCH & PARCH & TARCH \\
\hline Transaction Costs & 0.0691 & 0.0414 & 0.0495 & 0.0317 & 0.0437 \\
Annualized Return & $7.12 \%$ & $12.48 \%$ & $14.46 \%$ & $1.68 \%$ & $-7.05 \%$ & $\mathbf{1 4 . 8 4 \%}$ \\
\hline
\end{tabular}

Based onthe table 14, it can be mentioned that after considering transaction costs in case of out-of-sample trading performance, the TARCH model outperforms other models in the light of annualized return, since it has the highest annualized return (including transaction costs) at $14.84 \%$.

\section{Conclusion}

GARCH, EGARCH, PARCH, and TARCH models are benchmarked with an AR model, and an ARMA model in the study. The data consisted of exchange rates of Bangladeshi Taka (BDT) against the U.S. Dollar (USD) for the period of July 03, 2006 to April 30, 2012.

Both the estimated AR and ARMAmodels showthat their coefficients (with the exception of the constants) aresignificant. GARCH model demonstrates that in the variance equation, the coefficient of the terms, $\operatorname{RESID}(-1)^{\wedge} 2$ and $\operatorname{GARCH}(-1)$ are significant which indicatethat the volatility of risk is affected, significantly, by past square residual terms andpast volatility of exchange rate is significantly, influencing current volatility respectively. TARCH model shows that in the variance equation, all the coefficients of the terms, $\operatorname{RESID}(-1)^{\wedge} 2$, $\operatorname{RESID}(-1)^{\wedge} 2 *(\operatorname{RESID}(-1)<0)$, and $\operatorname{GARCH}(-1)$, are statistically significant which indicate that past volatility of exchange rate is significantly, influencing current volatility.TARCH model demonstrates thatinthe variance equation, all the coefficients of the terms, $(\operatorname{ABS}(\operatorname{RESID}(-1)), \operatorname{RESID}(-1))^{\wedge} \mathrm{C}(6)$, and @ $\operatorname{SQRT}(\mathrm{GARCH}(-1))^{\wedge} \mathrm{C}(8)$ are statistically significant which signify that past volatility of exchange rate is significantly, influencing current volatility. EGARCH model depicts that in the variance equation, all the coefficients of the terms, ABS(RESID(-1)/@SQRT(GARCH(-1))),RESID(-1)/@SQRT(GARCH(-1)), and LOG(GARCH(-1)) are statistically significant which indicatethat past volatility of exchange rate is significantly, influencing current volatility. Its variance equation also signifies that there exists the asymmetric behavior in volatility which means that positive shocks are effecting, differently, than the negative on volatility.

The in-sample statistical performance results select both the AR and ARMA models as the best performing model, whereas according to out-of sample statistical performance results, the GARCH model is the best performing model. Both the ARMA and AR models are selected as thebest model as per in -sample trading 
performanceoutcomes, whereas, TARCH model is nominated as the best model according to out - of - sample trading performanceoutcomes without transaction costs. As per in-sample and out-of-sample trading performance outcomes, the EGARCH and TARCH models outperformother models respectively with transaction cost.

\section{References}

Balg, B. A., \& Metcalf, H. (2010). Modelling exchange rate volatility. Review of International Economics, 18(1), 109-120.http://dx.doi.org/ 10.1111/j.1467-9396.2009.00872.x.

Bollerslev, T. P. (1986). Generalized autoregressive conditional heteroscedasticity. J. Econ., 31, 307-327.

Brooks, C. (2008). Introductory econometrics for finance (2nd ed.). Cambridge: Cambridge University Press.

Chong, C. W., Chun, L. S., \& Ahmad, M. I. (2002). Modelling the volatility of currency exchange rate using GARCH model. Pertanika J. Soc. Sci. \& Hum, 10(2), 85-95

Ellahi, N. (2011). Exchange rate volatility and foreign direct investment (FDI) behavior in Pakistan: A time series analysis with auto regressive distributed lag (ARDL) application. African Journal of Business Management, 5(29), 11656-11661. http://dx.doi.org/10.5897/AJBM11.1676

Glosten, L. R. et al. (1993). On the relation between the expected value and the volatility of the nominal excess return on stocks. J. Finance, 48, 1779-1801.

Hanke, J. E., \& Wichern, D. W. (2009). Business forecasting. ( $9^{\text {th }}$ ed). London : Person Prentice Hall

Hasan, V. (2005). Exchange rate volatility in Turkey and its effect on trade flows. Journal of Economic and Social Research, 4(1), 83-99.

Hooper, V. J., Reeves, J. J., \& Xie, X. (2009). Optimal modelling frequency for foreign exchange volatility forecasting. Applied Financial Economics, 19, 1159-1162.

Kamal, Y. Haq, M., Ghani, O., \& Khan, M. M. (2012). Modelling the exchange rate volatility, using generalized autoregressive conditionally heteroscedastic $(\mathrm{GARCH})$ type models: Evidence from Pakistan. African Journal of Business Management, 6(8), 2830-2838.http://dx.doi.org/10.5897/AJBM10.1657

Kemal, M. A. (2005). Exchange rate instability and trade: The case of Pakistan. PIDE publications.

Kun, H. (2011). Modelling volatility of S\&P 500 index daily return: a comparison between model based forecast and implied volatility. Thesis, Hanken School of Economics.

Madura, J. (2006). International financial management ( $8^{\text {th }}$ ed.). Mason: Thomson.

Mckenzie, M., \& Mitchell,H. (2002). Generalized asymmetric power ARCH modelling of exchange rate volatility.Applied Financial Economics, 12, 555-564.

Minkah, R. (2007). Forecasting volatility.U.U.D.M.Project Report, 7, Uppsala University.

Narayan, P. K., Narayan, S., \& Prasad, A. (2009). Modelling Fiji-US exchange rate volatility. Applied Economics Letters, 16, 831-834

Neely, C. J., \& Weller, P. A. (2009). Predicting exchange rate volatility: genetic programming vs. GARCH and riskmetrics.Working Paper: 2001-009B.

Nelson, D. (1991). Conditional heteroscedasticity in asset returns: A new approach. Econ., 59(2), 347-370.

Ngouana, C. L. (2012). Exchange rate volatility under peg: do trade patterns matter? IMF Working Paper.African Department.WP/12/73.

Sengupta, K. J. (2002). Modelling exchange rate volatility.Department of Economics.UCSB. Departmental Working Papers, 12-96.

So, M. K. P., Lam, K., \& Li, W. K. (1999).Forecasting exchange rate volatility using autoregressive random variance model. Applied Financial Economics, 9,583-591.

Taylor, S. (1986). Modelling financial time series. New York: John Wiley and Sons.

Zakoïan , J. M. (1994). Threshold heteroskedasticmodels. J. Econ. Dynam. Cont. Elsevier, 18(5), 931-955.

\section{Appendices}

1. Statistical Performance Measures

$$
\operatorname{MAE}=\left(\frac{1}{n}\right) \sum_{\tau=1+t}^{t+n} \mathrm{I} \widehat{\sigma}_{\tau}-\sigma_{\tau} \mathrm{I}
$$




$$
\begin{gathered}
\text { RMSE }=\sqrt{\left(\frac{1}{n}\right) \sum_{\tau=t+1}^{t+n}\left(\hat{\sigma}_{\tau}-\sigma_{\tau}\right)^{2}} \\
\text { Theil-U }=\frac{\sqrt{\left(\frac{1}{n}\right) \sum_{\tau=t+1}^{t+n}\left(\widehat{\sigma}_{\tau}-\sigma_{\tau}\right)}}{\sqrt{\frac{1}{n} \sum_{\tau=t+1}^{t+n} \widehat{\sigma_{\tau}^{2}}+\sqrt{\frac{1}{n} \sum_{\tau=t+1}^{t+n} \sigma_{\tau}^{2}}}}
\end{gathered}
$$

2. Trading Performance Measure

$$
\begin{gathered}
R^{A}=252 * \frac{1}{N} \sum_{t=1}^{N} R_{t} \\
R^{C}=\sum_{t=1}^{N} R_{t} \\
\sigma^{A}=\sqrt{252} * \sqrt{\frac{1}{N-1} * \sum_{t=1}^{N}\left(R_{t}-\bar{R}\right)^{2}} \\
\mathrm{SR}=\frac{R^{A}}{\sigma^{A}} \\
\left.\mathrm{MD}=\operatorname{Min}_{i=1, \ldots ., t ; t=1, \ldots \ldots ., N} \sum_{j=i}^{t} R_{j}\right)
\end{gathered}
$$

3. Output of AR(1) Model

\begin{tabular}{|c|c|c|c|c|}
\hline Variable & Coefficient & Std. Error & t-Statistic & Prob. \\
\hline $\mathrm{C}$ & $2.90 \mathrm{E}-05$ & 0.000107 & 0.271749 & 0.7859 \\
\hline $\mathrm{AR}(1)$ & -0.283417 & 0.030235 & -9.373657 & 0.0000 \\
\hline R-squared & \multicolumn{2}{|c|}{ 0.080326Mean dependent var } & & $2.89 \mathrm{E}-05$ \\
\hline Adjusted R-squared & \multicolumn{2}{|c|}{ 0.079411 S.D. dependent var } & & 0.004527 \\
\hline S.E. of regression & \multicolumn{2}{|c|}{ 0.004344Akaike info criterion } & & -8.038064 \\
\hline Sum squared resid & \multicolumn{2}{|c|}{0.018983 Schwarz criterion } & & -8.028310 \\
\hline Log likelihood & \multicolumn{2}{|c|}{ 4053.184Hannan-Quinn criter. } & & -8.034358 \\
\hline F-statistic & \multicolumn{2}{|c|}{ 87.86545Durbin-Watson stat } & & 2.019251 \\
\hline Prob(F-statistic) & \multicolumn{2}{|l|}{0.000000} & & \\
\hline
\end{tabular}

Dependent Variable: RETURN

Method: Least Squares

Date: 06/20/12Time: 02:33

Sample (adjusted): 21009

Included observations: 1008 after adjustments

Convergence achieved after 3 iterations

Inverted AR Roots

$-.28$ 
4. Output of ARMA(1,1) Model

Dependent Variable: RETURN

Method: Least Squares

Date: 06/20/12Time: 03:16

Sample (adjusted): 21009

Included observations: 1008 after adjustments

Convergence achieved after 6 iterations

MA Backcast: 1

\begin{tabular}{lccrr}
\hline \multicolumn{1}{c}{ Variable } & Coefficient & Std. Error & t-Statistic & Prob. \\
\multicolumn{1}{c}{ C } & $1.78 \mathrm{E}-05$ & $8.23 \mathrm{E}-05$ & 0.216817 & 0.8284 \\
\multicolumn{1}{c}{ AR(1) } & 0.185505 & 0.086423 & 2.146480 & 0.0321 \\
MA(1) & -0.505836 & 0.075954 & -6.659750 & 0.0000 \\
\hline R-squared & 0.099718Mean dependent var & & $2.89 \mathrm{E}-05$ \\
Adjusted R-squared & 0.097926S.D. dependent var & & 0.004527 \\
S.E. of regression & & 0.004300 Akaike info criterion & & -8.057391 \\
Sum squared resid & & 0.018583 Schwarz criterion & & -8.042761 \\
Log likelihood & & 4063.925Hannan-Quinn criter. & & -8.051833 \\
F-statistic & & 55.65839 Durbin-Watson stat & & 1.973798 \\
Prob(F-statistic) & & & & \\
Inverted AR Roots & .0 .000000 & & \\
Inverted MA Roots & .519 & & & \\
& & & & \\
\end{tabular}

